The Bangladesh Veterinarian (2012) 29(1) : 22 - 30

\title{
Shelf-life of Dahi (Yogurt) with or without potato mash
}

\author{
M. R. Amin, M. N. Islam*, M. A. Habib ${ }^{1}$ and F. Islam \\ Department of Dairy Science, Faculty of Animal Husbandry, Bangladesh Agricultural \\ University, Mymensingh-2202, Bangladesh
}

\begin{abstract}
Four different types of Dahi (Yogurt) were prepared and kept at room and refrigeration temperatures with different concentrations of potato mash $(0,5,10$ and $15 \%)$. These Dahi samples were analyzed for smell and taste, body and consistency, colour, texture and acidity and $\mathrm{pH}$ at pre and post storage period. The quality of Dahi deteriorated quickly at room temperature than at refrigeration temperature. With $(5 \%)$ or without potato mash keeping quality was preserved for up to three days but at refrigeration temperature they were suitable up to 12 days. Addition of $10 \%$ and $15 \%$ potato mashes were suitable for keeping Dahi up to two days at room temperature while in refrigeration temperature it was acceptable up to ten and eight days, respectively. Preparation of Dahi in incorporating potato mash may be economically feasible without compromising it qualities. (Bangl. vet. 2012. Vol. 29, No. 1, 22 - 30)
\end{abstract}

\section{Introduction}

Although, Dahi and Yogurt are more or less similar dairy products but there are some differences between them. Yogurt is prepared using the starter organisms: Streptococcus thermophilus and Lactobacillus bulgaricus, in a proportion of $1: 1$ with higher temperature $\left(40-50^{\circ} \mathrm{C}\right)$ and shorter incubation period $(3-4 \mathrm{~h})$, whereas Dahi is prepared by using mixed culture of Streptococcus lactis, Lactobacillus bulgaricus, Srteptococcus thermophilus, Streptococcus citrophilus, Lactobacillus planetonium with lower temperature $\left(37-42^{\circ} \mathrm{C}\right)$ and long incubation period $(8-15 \mathrm{~h})$. Comparatively curd of Yogurt is softer than the Dahi curd. A good quality Dahi should have smooth surface, firm body with marked acid flavour, no proteolysis, no gassiness, and no crack in cut surface.

Different types of Dahi, such as sweet Dahi, sour Dahi and flavoured Dahi are available in the market. Sweet Dahi is generally prepared from a mixed culture of Streptococcus lactis, Streptococcus thermophilus and Streptococcus citrophilus, sugar is usually added at the rate of $8-10 \%$ of volume of milk. Sour Dahi is generally prepared by seeding milk with a combination of Streptoccous thermophilus and Lactobacillus bulgaricus without sugar. Flavoured Dahi is made by the addition of synthetic flavour or natural fruit juice and sometimes by adding slice of seasonal

\footnotetext{
1Department of Animal Breeding and Genetics, Faculty of Animal Husbandry, Bangladesh Agricultural University, Mymensingh-2202, Bangladesh

*Corresponding author:- E-mail: ahsan.rony@yahoo.com
} 
fruits, flavourings, sugar and colour can be added prior to fermentation. Shakeel et al. (1994) successfully used mango juice to enrich the quality of sweet Dahi. Soya milk, sunflower proteins were used in the manufacture of yogurt (Hardi and Novakovic, 1994). Though, milk price and demand is increasing day by day, researchers are now thinking to add some milk replacer in partial amount like fruit juice (Desai et al., 1994; Shukla, 1982), soybean and powder milk to prepare Dahi.

No work has yet been done in Bangladesh to manufacture Yogurt or Dahi by using potato. Potato as a source of energy, may contribute not only energy but also substantial amounts of protein and essential vitamins, minerals and trace element of the human diet (Horton and Houghland, 1987). It is possible to use potato mash during preparation of Dahi to improve its texture and consistency, an important factor for popularization among consumers. But, question may arise for the preservative quality (shelf-life) of potato made Dahi. There are no comprehensive precise reports available and as such this study was undertaken to assess the shelf-life of Dahi using potato mash at different concentrations.

\section{Materials and Methods}

Chemical analysis of whole milk

Before preparing Dahi, initial quality of collected milk from the university dairy farm was estimated for specific gravity, total solids (TS; \%), solids-not-fat (SNF; \%), fat $(\%)$, acidity $(\%)$, protein (\%), ash (\%), moisture (\%) and $\mathrm{pH}$ value. Protein content was measured by micro-Kjeldahl method (AOAC, 1990). Fat was determined by the Gerber method (Bradly et al., 1992). Ash content was determined by dry ashing of the samples for 24 hours at $550^{\circ} \mathrm{C}$. Total solids content was determined by gravimetric method by drying the samples in an oven at $105^{\circ} \mathrm{C}$ for 24 hours (AOAC, 1990). Total titratable acidity was determined by AOAC (1990) method. The $\mathrm{pH}$ was measured using an electric digital $\mathrm{pH}$ meter (HANNA- $\mathrm{pH}$ 210, Germany) according to AOAC (1990).

\section{Preparation of potato mash}

The purchased potato was weighed with the help of balance and boiled, and the skin was separated with the help of clean hand. Black spotted diseased potatoes were removed. Then the potato was mashed by clean hand, kept in different plastic cups and stored at refrigeration temperature $\left(5^{\circ} \mathrm{C}\right)$ until used.

\section{Preparation of plain Dahi}

Required amount of milk boiled for about 10 minutes to reduce some volume of milk and also to destroy the viable organisms. At the boiling time, sugar was added at the rate of $8 \%$. During heating, milk was stirred thoroughly with the help of a stirrer. After desired heating milk pan was taken out from the heater and allowed to cool down near $42^{\circ} \mathrm{C}$ and inoculated with $2 \%$ starter cultures collected from local market. After inoculation warm milk of $42^{\circ} \mathrm{C}$ was then poured into several pre washed plastic 
cups and kept undisturbed at an incubation temperature of $37^{\circ} \mathrm{C}$ until complete coagulation. After complete coagulation $(5-8 \mathrm{~h})$, the Dahi samples were taken out from the incubator and were stored in a refrigerator at about $5^{\circ} \mathrm{C}$ for further analysis. This type of Dahi was designated as type "A" Dahi for the study purpose.

\section{Preparation of Dahi mixed with potato mash}

The preparation of Dahi with potato mash is similar with the preparation of plain Dahi. Potato mash @ 5, 10 and 15\% was added during boiling and was blended for proper mixing. After proper heating, the milk pan was taken out from the heating source and was kept to cool down to $42^{\circ} \mathrm{C}$. At that time starter culture @ 2\% was added and was kept in an incubator at $37^{\circ} \mathrm{C}$ until the complete coagulation $(5-8 \mathrm{~h})$. Then the Dahi samples were stored at about $5^{\circ} \mathrm{C}$ in the refrigerator until used.

Four different types of Dahi were prepared and designated as: i) Type A Dahi (plain Dahi without adding potato mash), ii) Type B Dahi (added 5\% potato mash in milk), iii) Type C Dahi (added 10\% potato mash in milk) and iv) Type D Dahi (added $15 \%$ potato mash in milk).

\section{Shelf-life assessment}

In this case, the prepared Dahi samples were preserved at room temperature $\left(32^{\circ} \mathrm{C}\right)$ and refrigeration temperature $\left(5^{\circ} \mathrm{C}\right)$ to assess the shelf-life. The qualities of Dahi were assessed as: (a) Physical tests: i) Smell and taste (50 marks), ii) Body and consistency (30 marks) and iii) Colour and texture (20 marks) and (b) Chemical tests: i) Acidity test and ii) $\mathrm{pH}$ value.

At room temperature, the said parameters of four samples were measured every day for every sample but at refrigerator temperature the same tests were done every alternate day until spoilage was evident.

\section{Statistical design and data analysis}

All study materials were completely homogenous and statistical analysis done as per Steel and Torrie (1960) using Completely Randomized Design. Data collected were analyzed by using (MSTAT) statistical program.

\section{Results and Discussion}

Physical parameters

The plain Dahi and potato mashed Dahi were stored at room and refrigeration temperature and their qualities were measured with the help of some physical tests (smell and taste, body and consistency and colour and texture) by organoleptic evaluation and chemical tests (Acidity, $\mathrm{pH}$ ) and are presented in Table 1-4.

\section{Smell and taste}

Smell and taste score of different Dahi samples stored at different duration of 
room and refrigeration temperatures are presented in Table 1. Prior to storage, the smell and taste score of A, B, C and D Dahi samples were $48 \pm 1.5,49.0 \pm 1.0,49.0 \pm 1.2$ and $45.3 \pm 0.6$. After storage smell and taste score of the samples decreased rapidly at room temperature. Nahar et al. (2009) observed rapid decrease of smell and taste of Dahi added with $5 \%$ potato mash at room temperature. At room temperature smell and taste scores of A and B samples were acceptable up to three days (32.7 \pm 0.6 and $32.0 \pm 2.0)$, but for $C$ and $D$ samples, smell and taste scores were acceptable for two days only $(36.3 \pm 1.5$ and $32.0 \pm 1.7)$. At $4^{\text {th }}$ days of storage smell and taste scores of A and B become unacceptable and their scores were not recorded. Nahar et al. (2009) reported potato mash (5\%) Dahi to be acceptable stored at room temperature up to 24 hours. Sultana (2005) reported quick deterioration of Dahi at room temperature and acceptable for consumption up to three days.

Table 1. Sensory scores of smell and taste $($ score $=50)$ of different Dahi samples kept under room and refrigeration temperature

\begin{tabular}{c|ccc|c|c|c|c|c|c}
\hline \multirow{2}{*}{$\begin{array}{c}\text { Storage } \\
\text { days }\end{array}$} & \multicolumn{5}{|c|}{ Room temperature } & \multicolumn{4}{c}{ Refrigeration temperature } \\
\cline { 2 - 9 } & $\mathrm{A}$ & $\mathrm{B}$ & $\mathrm{C}$ & $\mathrm{D}$ & $\mathrm{A}$ & $\mathrm{B}$ & $\mathrm{C}$ & $\mathrm{D}$ \\
\hline 0 & $48.0 \pm 1.5$ & $49.0 \pm 1.0$ & $49.0 \pm 1.2$ & $45.3 \pm 0.6$ & $48.0 \pm 1.5$ & $49.0 \pm 1.0$ & $49.0 \pm 1.2$ & $45.3 \pm 0.6$ \\
1 & $44.3 \pm 0.6$ & $43.3 \pm 1.5$ & $42.0 \pm 0.0$ & $40.0 \pm 0.0$ & - & - & - & - \\
2 & $38.0 \pm 1.0$ & $37.0 \pm 1.0$ & $36.3 \pm 1.5$ & $32.0 \pm 1.7$ & - & - & - & - \\
3 & $32.7 \pm 0.6$ & $32.0 \pm 2.0$ & $29.7 \pm 2.0$ & $27.0 \pm 0.0$ & - & - & - & - \\
4 & - & - & - & - & $47.4 \pm 0.6$ & $46.3 \pm 1.5$ & $46.0 \pm 1.0$ & $42.0 \pm 0.0$ \\
6 & - & - & - & - & $44.0 \pm 1.0$ & $43.3 \pm 1.5$ & $42.3 \pm 0.0$ & $35.3 \pm 0.6$ \\
8 & - & - & - & - & $42.3 \pm 2.0$ & $41.3 \pm 1.5$ & $38.0 \pm 1.5$ & $31.0 \pm 1.0$ \\
10 & - & - & - & - & $38.0 \pm 2.0$ & $38.0 \pm 1.7$ & $32.3 \pm 0.6$ & $27.3 \pm 0.6$ \\
12 & - & - & - & - & $32.3 \pm 1.8$ & $31.3 \pm 1.6$ & $27.8 \pm 1.0$ & $20.7 \pm 0.6$ \\
14 & - & - & - & - & $28.3 \pm 1.5$ & $26.0 \pm 1.0$ & $22.0 \pm 1.2$ & $19.7 \pm 1.5$ \\
16 & - & - & - & - & $25.7 \pm 1.2$ & $23.3 \pm 1.5$ & $21.0 \pm 1.7$ & $16.0 \pm 0.0$ \\
\hline
\end{tabular}

On the other hand, smell and taste score of Dahi samples preserved at refrigeration temperature decreased slowly, which agrees well by Nahar et al. (2009). Smell and taste score of A and B samples in this situation was acceptable up to 12 days $(32.3 \pm 1.8$ and $31.3 \pm 1.6)$, whereas for $C$ and $D$ samples could be acceptable up to ten and eight days, respectively $(32.3 \pm 0.6$ vs $31.0 \pm 1.0)$. The result of this study agrees with the findings of Shukla (1982) who reported 10\% fruit yogurt could be stored just for a day at ambient temperature, whereas at refrigeration temperature could do well for about ten days without deterioration. Nahar et al. (2009) reported keeping quality of Dahi containing $5 \%$ potato mash to be acceptable up to 13 days stored at refrigerated temperature, which is in agreement with this study. In the present study, although, the Dahi sample that contained 5\% potato mash was good for three days at room temperature, but Dahi samples that contained $10 \%$ and $15 \%$ 
potato mash were good for two days at room temperature. The result indicates that addition of potato mash enhanced quick fermentation and for this reason the keeping quality of different levels of potato mash added Dahi was lower than plain Dahi.

\section{Body and consistency}

Before storage, body and consistency score of A, B, C and D Dahi samples were $27.0 \pm 1.0,29.0 \pm 1.0,28.7 \pm 1.2$ and $27.0 \pm 0.0$, respectively, (Table 2).

Table 2. Sensory scores of body and consistency (score $=30$ ) of different Dahi samples kept under room and refrigeration temperature

\begin{tabular}{c|ccc|c|c|c|c|c|c}
\hline \multirow{2}{*}{$\begin{array}{c}\text { Storage } \\
\text { days }\end{array}$} & \multicolumn{5}{|c|}{ Room temperature } & \multicolumn{4}{c}{ Refrigeration temperature } \\
\cline { 2 - 9 } & $\mathrm{A}$ & $\mathrm{B}$ & $\mathrm{C}$ & $\mathrm{D}$ & $\mathrm{A}$ & $\mathrm{B}$ & $\mathrm{C}$ & $\mathrm{D}$ \\
\hline 0 & $27.0 \pm 1.0$ & $29.0 \pm 1.0$ & $28.7 \pm 1.2$ & $27.0 \pm 0.0$ & $27.0 \pm 1.0$ & $29.0 \pm 1.0$ & $28.7 \pm 1.2$ & $27.0 \pm 0.0$ \\
1 & $25.3 \pm 2.0$ & $27.3 \pm 1.2$ & $27.3 \pm 1.2$ & $24.0 \pm 1.7$ & - & - & - & - \\
2 & $22.3 \pm 2.5$ & $26.0 \pm 1.7$ & $25.7 \pm 0.8$ & $22.0 \pm 2.1$ & - & - & - & - \\
3 & $18.3 \pm 2.0$ & $20.0 \pm 1.7$ & $18.3 \pm 2.4$ & $17.3 \pm 0.6$ & - & - & - & - \\
4 & - & $18.0 \pm 1.1$ & - & - & $25.3 \pm 1.7$ & $26.6 \pm 1.2$ & $27.0 \pm 1.0$ & $25.3 \pm 1.5$ \\
6 & - & - & - & - & $23.7 \pm 1.8$ & $26.7 \pm 1.5$ & $26.7 \pm 1.2$ & $22.3 \pm 2.0$ \\
8 & - & - & - & - & $22.3 \pm 1.2$ & $25.7 \pm 2.0$ & $24.3 \pm 0.6$ & $20.0 \pm 2.0$ \\
10 & - & - & - & - & $19.3 \pm 1.2$ & $23.7 \pm 2.0$ & $23.0 \pm 2.2$ & $18.3 \pm 1.5$ \\
12 & - & - & - & - & $19.0 \pm 1.7$ & $20.7 \pm 1.1$ & $20.3 \pm 0.6$ & $17.0 \pm 0.0$ \\
14 & - & - & - & - & $16.7 \pm 1.2$ & $18.0 \pm 1.0$ & $18.0 \pm 1.2$ & $16.0 \pm 1.0$ \\
16 & - & - & - & - & $14.7 \pm 1.2$ & $17.3 \pm 1.2$ & $16.0 \pm 2.0$ & $15.3 \pm 0.6$ \\
\hline
\end{tabular}

Body and consistency score of the Dahi samples decreased gradually depending on the days of storage life. Decreased in score was very rapid for the room temperature preserved samples. This is in agreement with Nahar et al. (2009). Body and consistency score was acceptable up to three days for A, C and D Samples (18.3 \pm $2.0,18.3 \pm 2.0$ and $17.3 \pm 0.6)$. On the other hand, body and consistency score was acceptable up to four days for B sample (18.0 \pm 1.1$)$, whereas Nahar et al. (2009) found it up to 24 hours for the same sample.

Body and consistency score decreased slowly in refrigerated samples. At refrigeration temperature $\left(5^{\circ} \mathrm{C}\right)$ body and consistency was acceptable up to $14^{\text {th }}$ days for B and C samples $(18.0 \pm 1.0$ and $18.0 \pm 1.2)$, up to $12^{\text {th }}$ days for A sample $(19.0 \pm 1.7)$ and up to $10^{\text {th }}$ days for D sample $(18.3 \pm 1.5)$. Nahar et al. (2009) got keeping quality of body and consistency of $5 \%$ potato mash added Dahi to be acceptable at refrigerated temperature up to nine days of storage, which is five days lower than our study. From the result, it is evident that smell and taste score become unacceptable little earlier than body and consistency score.

\section{Colour and texture}

Colour and texture score of all Dahi samples are given in Table 3. Initial colour 
and texture score of A, B, Cand D samples were $18 \pm 2.0,16.3 \pm 1.5$ and $16.3 \pm 1.5$, respectively. Like other physical tests mentioned earlier, colour and texture scores were decreased with progressing storage period. Deteriosion was rapid at room temperature $\left(32^{\circ} \mathrm{C}\right)$ than that of samples kept at refrigeration temperature $\left(5^{\circ} \mathrm{C}\right)$. This is in agreement with Nahar et al. (2009). In every case colour and texture of plain Dahi decreased little slowly than that of samples contained potato mash. Storage at room temperature, Dahi samples were acceptable for their colour and texture up to three days for $A, B$ and $C(15.3 \pm 1.2,15.0 \pm 1.2$ and $14.7 \pm 1.2)$, while for $\mathrm{D}(15.7 \pm 1.2)$ it was acceptable for two days. Nahar et al. (2009) reported acceptability of colour and texture of $5 \%$ potato mashed Dahi up to 24 hours storage at room temperature.

Table 3. Sensory scores of color and texture (scores $=20$ ) of different Dahi samples kept under room and refrigeration temperature

\begin{tabular}{c|ccc|c|c|c|c|c|c}
\hline \multirow{2}{*}{$\begin{array}{c}\text { Storage } \\
\text { days }\end{array}$} & \multicolumn{5}{|c|}{ Room temperature } & \multicolumn{4}{c}{ Refrigeration temperature } \\
\cline { 2 - 9 } & $\mathrm{A}$ & $\mathrm{B}$ & $\mathrm{C}$ & $\mathrm{D}$ & $\mathrm{A}$ & $\mathrm{B}$ & $\mathrm{C}$ & $\mathrm{D}$ \\
\hline 0 & $19.3 \pm 1.2$ & $18.0 \pm 2.0$ & $16.3 \pm 1.5$ & $16.3 \pm 1.5$ & $19.3 \pm 1.2$ & $18.0 \pm 2.0$ & $16.3 \pm 1.5$ & $16.3 \pm 1.5$ \\
1 & $18.3 \pm 1.5$ & $17.3 \pm 2.2$ & $15.7 \pm 1.2$ & $16.0 \pm 1.0$ & - & - & - & - \\
2 & $16.3 \pm 1.2$ & $17.0 \pm 2.5$ & $14.7 \pm 1.2$ & $15.7 \pm 1.2$ & - & - & - & - \\
3 & $15.3 \pm 1.2$ & $15.0 \pm 1.2$ & $14.7 \pm 1.2$ & $13.0 \pm 1.0$ & - & - & - & - \\
4 & - & - & - & - & $18.7 \pm 1.2$ & $17.7 \pm 1.7$ & $16.0 \pm 2.0$ & $16.0 \pm 2.0$ \\
6 & - & - & - & - & $18.7 \pm 1.1$ & $16.3 \pm 1.5$ & $15.3 \pm 1.2$ & $15.7 \pm 2.1$ \\
8 & - & - & - & - & $16.7 \pm 1.2$ & $14.7 \pm 2.0$ & $14.7 \pm 0.6$ & $14.6 \pm 1.2$ \\
10 & - & - & - & - & $16.0 \pm 1.7$ & $14.7 \pm 2.3$ & $12.0 \pm 0.0$ & $13.7 \pm 2.1$ \\
12 & - & - & - & - & $14.0 \pm 1.7$ & $13.3 \pm 1.1$ & $10.7 \pm 1.2$ & $13.0 \pm 1.7$ \\
14 & - & - & - & - & $13.0 \pm 1.0$ & $12.7 \pm 1.2$ & $10.0 \pm 0.0$ & $11.6 \pm 2.0$ \\
16 & - & - & - & - & $12.7 \pm 1.2$ & $11.3 \pm 1.2$ & $10.0 \pm 0.0$ & $10.7 \pm 1.2$ \\
\hline
\end{tabular}

On the other hand, at refrigeration temperature, colour and texture was acceptable up to 12 days for A $(14.0 \pm 1.7), 10$ days for B $(14.7 \pm 2.3)$ and eight days for $\mathrm{C}$ and D samples $(14.7 \pm 0.6,14.6 \pm 1.2)$. Nahar et al. (2009) reported acceptability up to 11 days at refrigerated temperature for colour and texture of $5 \%$ potato mash containing Dahi. This result is in agreement with them.

Acidity

Acidity of different Dahi samples is presented in Table 4. Immediately after preparation, the average acidity of $\mathrm{A}, \mathrm{B}, \mathrm{C}$ and D Dahi samples were $0.6 \pm 0.0,0.7 \pm 0.0$, $0.7 \pm 0.0$ and $0.7 \pm 0.0$. Acidity of all Dahi samples increased gradually depending on the storage time. Acidity of Dahi increased rapidly at room temperature but at refrigeration temperature acidity increased slowly. In both cases acidity was high in D sample and low in A sample.

From organoleptic evaluation, it has been mentioned earlier that at room temperature A and B Dahi samples were acceptable for consumption up to three days 
and for $\mathrm{C}$ and $\mathrm{D}$ it was two days. At two days of storage, acidity of $\mathrm{A}$ and $\mathrm{B}$ samples were $1.0 \pm 0.0$ and $1.1 \pm 0.0 \%$. On the other hand, acidity of $C$ and $D$ samples at one day of storage were $1.0 \pm 0.0$ and $1.0 \pm 0.0 \%$. Nahar et al. (2009) showed the shelf-life of $5 \%$ potato mashed Dahi at room temperature with spoilage after 24 hours of storage.

\section{Chemical test}

Table 4. Changes of chemical parameters (acidity and $\mathrm{pH}$ ) of different Dahi samples under room and refrigeration temperature

\begin{tabular}{c|ccc|c|c|c|c|c}
\hline \multirow{2}{*}{$\begin{array}{c}\text { Storage } \\
\text { days }\end{array}$} & \multicolumn{6}{|c|}{ Acidity (\%) } & \multicolumn{5}{c}{$\mathrm{pH}$} \\
\cline { 2 - 9 } & \multicolumn{7}{|c}{ Treatment group } & \multicolumn{5}{c}{ Treatment group } \\
\cline { 2 - 9 } & $\mathrm{A}$ & $\mathrm{B}$ & $\mathrm{C}$ & $\mathrm{D}$ & $\mathrm{A}$ & $\mathrm{B}$ & $\mathrm{C}$ & $\mathrm{D}$ \\
\hline \multicolumn{8}{c}{ Room temperature } \\
\hline 0 & $0.6 \pm 0.0$ & $0.7 \pm 0.0$ & $0.7 \pm 0.0$ & $0.7 \pm 0.0$ & $4.2 \pm 0.0$ & $4.2 \pm 0.0$ & $4.2 \pm 0.0$ & $4.2 \pm 0.0$ \\
1 & $0.9 \pm 0.1$ & $0.9 \pm 0.0$ & $1.0 \pm 0.2$ & $1.0 \pm 0.0$ & $4.1 \pm 0.1$ & $4.1 \pm 0.1$ & $4.0 \pm 0.1$ & $3.9 \pm 0.1$ \\
2 & $1.0 \pm 0.0$ & $1.07 \pm 0.04$ & $1.3 \pm 0.0$ & $1.3 \pm 0.0$ & $3.9 \pm 0.1$ & $3.8 \pm 0.0$ & $3.7 \pm 0.1$ & $3.5 \pm 0.1$ \\
3 & $1.4 \pm 0.0$ & $1.5 \pm 0.0$ & $1.5 \pm 0.0$ & $1.5 \pm 0.0$ & $3.1 \pm 0.2$ & $2.6 \pm 0.9$ & $2.9 \pm 0.2$ & $2.9 \pm 0.1$ \\
4 & $\mathrm{ND}$ & $\mathrm{ND}$ & $\mathrm{ND}$ & $\mathrm{ND}$ & $\mathrm{ND}$ & $\mathrm{ND}$ & $\mathrm{ND}$ & $\mathrm{ND}$ \\
\hline \multicolumn{8}{c}{ Refrigeration temperature } \\
\hline 0 & $0.6 \pm 0.0$ & $0.7 \pm 0.0$ & $0.7 \pm 0.0$ & $0.7 \pm 0.0$ & $4.2 \pm 0.0$ & $4.2 \pm 0.0$ & $4.2 \pm 0.0$ & $4.2 \pm 0.0$ \\
4 & $0.7 \pm 0.0$ & $0.7 \pm 0.0$ & $0.8 \pm 0.0$ & $0.8 \pm 0.0$ & $4.2 \pm 0.0$ & $4.17 \pm 0.0$ & $4.2 \pm 0.0$ & $4.2 \pm 0.0$ \\
6 & $0.8 \pm 0.0$ & $0.8 \pm 0.0$ & $0.8 \pm 0.0$ & $0.8 \pm 0.0$ & $4.2 \pm 0.0$ & $4.2 \pm 0.0$ & $4.1 \pm 0.0$ & $4.1 \pm 0.0$ \\
8 & $0.8 \pm 0.0$ & $0.8 \pm 0.0$ & $0.8 \pm 0.0$ & $0.8 \pm 0.0$ & $4.2 \pm 0.0$ & $4.2 \pm 0.0$ & $4.1 \pm 0.0$ & $4.1 \pm 0.0$ \\
10 & $0.8 \pm 0.0$ & $0.8 \pm 0.0$ & $0.9 \pm 0.0$ & $0.9 \pm 0.0$ & $4.2 \pm 0.0$ & $4.1 \pm 0.0$ & $4.1 \pm 0.0$ & $4.0 \pm 0.1$ \\
12 & $0.9 \pm 0.0$ & $1.0 \pm 0.0$ & $1.2 \pm 0.0$ & $1.2 \pm 0.0$ & $4.0 \pm 0.0$ & $4.0 \pm 0.0$ & $3.9 \pm 0.1$ & $3.7 \pm 0.2$ \\
14 & $1.1 \pm 0.1$ & $1.2 \pm 0.0$ & $1.2 \pm 0.0$ & $1.3 \pm 0.1$ & $3.8 \pm 0.1$ & $3.7 \pm 0.1$ & $3.6 \pm 0.0$ & $3.4 \pm 0.1$ \\
16 & $1.2 \pm 0.1$ & $1.3 \pm 0.1$ & $1.3 \pm 0.0$ & $1.4 \pm 0.1$ & $3.6 \pm 0.1$ & $3.5 \pm 0.1$ & $3.7 \pm 0.6$ & $3.1 \pm 0.1$ \\
\hline
\end{tabular}

At refrigeration temperature A sample was acceptable up to 14 days and at that time acidity was $1.1 \pm 0.1 \%$, whereas, sample B was acceptable up to 12 days and at that time acidity was $1.0 \pm 0.0 \%$. It was observed that $C$ and $D$ samples were acceptable for consumption up to ten days and at that time their acidity for both the samples were $0.9 \pm 0.0$.

The result of this study agrees with the findings of Osborne and Pritchard (1974) who reported yogurt containing $12.5 \%$ fruit had a shelf-life up to 14 days at $5^{\circ} \mathrm{C}$, six days at $8-10^{\circ} \mathrm{C}$ and one day at ambient temperature. In another study, Nahar et al. (2009) reported shelf-life of Dahi having had acidity with 5\% potato mash that spoiled after 11 days storage at refrigerated temperature. Similarly, Shukla (1982) found that fruit yogurt could be stored just for a day at ambient temperature, whereas at refrigeration temperature $\left(5^{\circ} \mathrm{C}\right)$ it can be preserved for ten day. In our study, acidity development was rapid at room temperature. This could be due to the fact that room 
temperature during the study period was 30 to $32^{\circ} \mathrm{C}$, which is suitable for rapid multiplication of acid producing bacteria. As the population of microorganism increased rapidly, fermentation of lactose took place quickly and as a result more lactic acid produced at room temperature. On the other, at $5^{\circ} \mathrm{C}$ refrigeration the growth of acid producing bacteria hampered. As a result acid production was slow in refrigerated samples. Acid production of $C$ and $D$ samples were higher than that of $A$ and B samples and lowest acidity always seen in A sample. This was probably due to the fact that during incorporation of potato mash in milk, microorganisms might have entered in milk, which might have encouraged milk fermentation, thus helped to increase the acid percent in $\mathrm{C}$ and $\mathrm{D}$ samples.

pH value

Average $\mathrm{pH}$ values of $\mathrm{A}, \mathrm{B}, \mathrm{C}$ and $\mathrm{D}$ Dahi samples immediately after preparation were $4.2 \pm 0.0,4.2 \pm 0.0,4.2 \pm 0.0$ and $4.2 \pm 0.0$, respectively (Table 4 ). $\mathrm{pH}$ values of all samples decreased with progressing storage period. The changes of $\mathrm{pH}$ values of samples are given in Table 4. It is mentioned earlier that acidity of all Dahi samples were increased with elapse of storage time. Logically, it is usual for decreasing $\mathrm{pH}$ values with increasing storage time. The decrease of $\mathrm{pH}$ was rapid at room temperature and slow in refrigeration temperature. This result agrees well with the finding of Nahar et al. (2009). The result of $\mathrm{pH}$ value agrees with the earlier work of Kondratenko et al. (1978), who reported decreased $\mathrm{pH}$ value of Dahi samples with storage time.

\section{Conclusions}

Considering the shelf-life assessment of Dahi samples, it is suggested that potato mash $(5 \%)$ may be added for improving the quality of Dahi that can be consumed up to three days at room temperature and 12 days at refrigeration temperature.

\section{References}

AOAC 1990: Official methods of analysis of the association of official analytical chemists, $15^{\text {th }}$ edition, Virginia 22201, Arlington, USA.

Bradly Jr. RL, Arnold Jr. E, Barbano DM, Semerad RG, Smith DE, Vines BK 1992: Chemical and physical methods. In: Marshall TR, Standard methods for the microbiological examination of dairy products, $16^{\text {th }}$ edition, American Public Health Association, Washington DC, USA.

Desai SR, Tono VA, Joshi SV 1994: Utilization of different fruits in the manufacture of yogurt. Indian Journal of Dairy science 47 870-874.

Hardi J, Novakovic P 1994: The feasibility of yogurt manufacture using cow milk and Soya milk blends. Dairy Science Abstract 56725.

Horton AE, Houghland ME 1987: Commercial potato production. US Department of Agriculture Service, Agriculture Hand Book pp. 267. 
Kondratenko MS, Goranova L, Simenova R 1978: International Dairy Science Congress E 10 3-14.

Nahar A, Al-Amin M, Akter N, Nahar N 2009: Evaluation of the Shelf-life of Dahi (Yoghurt) at different temperature depending on its consistency quality. Bangladesh Research Publications Journal 3 897-908.

Osborne RJ, Pritchard, EW 1974: XIX International Dairy Congress IE, pp. 809.

Shakeel A, Thompkinson DK, Aagar S 1994: Manufacture of fruit flavored filled bioyogurt. Indian Journal of Dairy Science 47 695-701.

Shukla FC 1982: The effect of packaging material on the quality of fruit yogurt. PhD Thesis, Punjab Agricultural University, Ludhian, India, pp. 315.

Steel RGD, Torrie JH 1960: Principles and Procedures of Statistics. McGraw-Hill Book Company. Inc. New York, USA.

Sultana N 2005: Preparation of Dahi from buffalo milk with the addition of different levels of soya milk. MS Thesis, Department of Dairy Science, Faculty of Animal Husbandry, Bangladesh Agricultural University, Mymensingh, Bangladesh. 